\title{
Ubiquidade etnográfica: original fake, codex expandido, sujeito transurbano, manequim performática
}

MASSIMO CANEVACCI

Resumo

O ensaio presenta a emergência do fake, um conceito que não significa falso, mas falso/verdadeiro, a causa da comunicação digital. Nesse sentido, também um complexo arquitetônico da famosa Zaha Hadid é copiado e realizado antes do original. A relação cultura digital/sujeito ubíquo é determinante nesse processo, onde a relação entre reprodutibilidade e aura não pode ser mais como Benjamin imaginou, dialética e dualista, mas vira sempre mais um cruzamento que "reproduz" a aura. A metrópole comunicacional vira sempre mais performática no sentido espontâneo e público: assim na conclusão analiso a presença perturbadora de bonecas "viventes".

Palavras-chave:

Ubiquidade, transurbano, autorrepresentação 


\title{
Ethnographic ubiquity: original fake, expanded codex, transurban subject, performative doll
}

\begin{abstract}
My essay presents the emerging of fake as a concept that does not mean false, but a post-dualistic mix of false/truth. The relation between digital culture and ubiquitous subjectivity is fundamental during its process; in the same way, the relation between aura and reproducibility cannot be determined dialectically as Benjamin did. Digital auratic reproducibility is the contemporary context and communicational metropolis is characterized by spontaneous and public performance: so, my conclusion is an analysis of some "living" doll and their uncanny presence.
\end{abstract} self-representation 


\section{Introdução}

No final do ano passado, 2012, uma notícia esclareceu uma tendência que poderia ser sempre mais determinante nas artes visuais em geral: "Copycat Architects in China Take Aim at the Star". A estrela é aquela que é não só uma arquiteta, mas, como vou aprofundar depois, Zaha Hadid é para mim a maior filósofa visual e etnógrafa urbana da contemporaneidade. Ela está no processo de construir uma nova futuristic Galaxy $\mathrm{SOHO}$ Complex, a Guangzhou, e descobriu que os "piratas" estão a sua frente, tentando copiar Wanjing Complex em Chongqing, uma enorme metrópole com cerca de 30 milhões de moradores: "The project being pirated is the Wangjing $\mathrm{SOHO}$, a complex of three towers that resemble curved sails, sculpted in stone and etched with wave-like aluminum bands, that appear to swim across the surface of the Earth when viewed from the air" (PLATT, 2012).

A China pode copiar tudo. O problema é que copiar antes do original um complexo arquitetônico de três enormes edifícios super complexos é uma extrema novidade. É "a" novidade. Novidade na esfera mutante daquilo que chamamos artes contemporâneas. A aura está virando reproduzível também na arte mais sólida. Photoshop e arquitetura: "Could there one day appear an entire Chinese cosmopolis populated by mutant versions of the cool crystal-shaped cultural centers crafted by Zaha Hadid? Could China see the proliferation of 10 or 20 architectural clones of the Guangzhou Opera House spread out across its leading megacities?" (ibidem)

\section{Arte Ubíqua}

O conceito de ubíquo se apresenta em torno de um método de pesquisa de campo - a etnografia - indisciplinado, ou seja, que 
recusa os limites das disciplinas diversas institucionalizadas. Nos últimos anos, o conceito de ubiquidade mudou o sentido do seu próprio significado e proliferou um disseminado uso metafórico para identificar as experiências subjetivas através da comunicação digital. Como consequência, a relação entre web e metrópole tornou-se ubíqua: a ubiquidade comunicacional caracteriza as relações espaço-temporais na cotidianidade banal assim como as visões artísticas.

A acepção atual de tal conceito herda e expande o de cronotopo elaborado pelas ciências literárias e antropológicas. A sua matriz científica - no sentido de ciências chamadas exatas - é transformada por Bakhtin (1988) numa metodologia a ser aplicada nos romances do secúlo XIX. O cronotropo, unificando aquilo que eram os a-priori, determina uma visão da escritura na qual espaço-tempo apresentam uma dinâmica na qual o herói assume papeis ou estilos discursivos que o autor descentra em cada personagem, nos desdobramentos dialógicos. O cronotropo é pressuposto para o desenvolvimento descentrado da polifonia literária, onde as subjetividades se multiplicam nas suas específicas e irredutíveis individualidades. O herói não é mais projeção monológica do autor, mas cada personagem desenvolve uma autonomia linguística e psicológica. Isto é, polifônica.

Um outro conceito afim a ambos é o de "simultaneidade". Os futuristas amaram tal conceito aplicando-o tanto nas artes plásticas (pintura e escultura) como nas performáticas, nas quais as declamações de poesia, músicas, contos eram representadas simultaneamente nos palcos. Esta escolha expressiva é de fundamental interesse para o meu discurso: os futuristas foram os primeiros que, como vanguarda, amaram a metrópole contraposta ao tédio da campanha e aos clarões da lua. Na metrópole-que-sobe, Marinetti ${ }^{1}$ percebe o emerge de panoramas dissonantes, extensões corpóreas, rumores deslocados: de todas aquelas sensorialidades que são aumentadas simultaneamente na experiência tecnológica urbana.

A simultaneidade se apresenta, a meu ver, como a irmã "material" da ubiquidade. Talvez seja quase filha do cinema nascente, que na montagem exprime uma contiguidade ótica entre segmentos narrativos diversos. Para os futuristas, a simultaneidade é experiência estética feita de enxertos fragmentados entre metrópole e tecnologia; um pulsar expressivo de imagens ou parolibere ("palavras - livres") de consecutio é possível graças a um sujeito igualmente simultâneo: o futurista. Aquele que tem a subjetividade adestrada para entender flexibilidades 
estendidas entre os espaços-tempos vividos nos panoramas urbanos. Tal ótica simultânea é poesia para um futuro anunciado nos movimentos icônico-sônicos que nascem na rua, atravessam a janela do atelier e se posicionam na tela do pintor e na partitura do musicista simultaneamente. A rua é arte urbana.

Acenei à dimensão só material que caracteriza a simultaneidade. Ao contrário, o conceito de ubíquo é desvinculado de tal matriz empírica. Talvez a maior autonomia filosófica derive de ser - a ubiquidade - uma condição abstrata já ligada misticamente a um ser divino. O ubíquo não é o resultado da experiência empírica na vida cotidiana como o simultâneo; ao contrário, este pertence a uma percepção visionária do invisível no qual a condição humana é constantemente observada pelo divino e do qual não foge escondendo-se em algum lugar secreto, porque o ("o ser") que é ubíquo o encontra por que o transcende.

Na contemporaneidade, o ubíquo desenvolve a imanência lógico-sensorial de caráter material/imaterial; exprime tensões além do dualismo, ou seja, aquele sentir simplificado da condição humana na qual as oposições binárias são funcionais a reconduzir a complexidade cotidiana no domínio dicotômico da ratio. Ubíquo é incontrolável, incompreensível, indeterminável. Fora do controle político vertical, da racionalidade mono-lógica, de qualquer determinação linear espaço/temporal. Nesta perspectiva, é possível arrancar a sua apropriação indébita daquilo que é definido como deus e em consequência elaborar visões ubíquas para as invenções humanistas que se movem à margem do além: além da fixidez identitária das coisas e do ser que, por tal qualidade, oferece visões poéticas-políticas ilimitadas.

Ubíquo é a potencialidade da fantasia que conjuga espaços públicos e tecnologia.

O campo se dilatou, se estendeu numa simultaneidade diaspórica, digital e multividual, na qual é cada vez mais imanente a ubiquidade material/imaterial.

Tal ubiquidade da etnografia requer ser penetrada e precisada. A minha identidade de pesquisador não permanece idêntica a si mesma, porque desenvolve ao mesmo tempo relações diagonais que usam diferenciadas expressões metodológicas em diversas zonas glocais cada vez menos caracterizadas geograficamente e cada vez mais subjetiva e emocionalmente. Tal identidade é mais flexível em relação ao passado industrialista, é uma identidade em parte mutante acomodada num barco instável, que oscila entre diversos sujeitos/contextos no mesmo frame. Por isto o olho etnográfico/ 
artístico é ubíquo enquanto adestrado para decodificar a coexistência de códigos discordantes (escritos, visuais, musicais, mixados etc.) e a praticar módulos igualmente diferenciados.

As coordenadas espaço-temporais se tornam tendencialmente supérfluas e se expande um tipo de experiência subjetiva ubíqua. $\mathrm{O}$ artista se coloca em tal situação de ubiquidade imerso na própria experiência pessoal e na relação instantânea com o outro. E este outro é igualmente ubíquo, no sentido que vive onde está ativo naquele momento o seu sistema comunicacional digitalizado. Tal experiência não significa desmaterialização das relações interpessoais; atesta uma complexa rede psico-corpórea, conexões óticas e manuais, seguramente cerebrais e imaginárias que deslocam também na aparente imobilidade a experiência do sujeito. O conceito de multivíduo se manifesta plenamente em tais conexões ubíquas. A etnografia ubíqua expande multividualidades conectivas. São tramas que conectam fragmentos e espaços/tempos sem aquela identificação determinada "normal" e que multiplicam identidades/identificações temporárias. O sujeito da experiência etnográfica ubíqua é multividual.

A montagem interna caracteriza tal condição, enquanto a montagem tradicional externa conjuga consecutivamente fragmentos de histórias separadas entre si logicamente ou espacialmente, a interna - favorecida pela morphing digital (Sobchack, 200o), mas já praticada pela collage analógica multiplica a quantidade/qualidade de códigos coexistentes por unidade de imagem. A montagem interna dilata a percepção ótica da simultaneidade e a expande na ubiquidade. Simetrias se apresentam entre a montagem interna oferecida ao olhar ubíquo e o novelo multividual: entre as malhas simultâneas do cut-up - e o cacho de "eus" (o eus), que se conecta ou desconecta em espaços/tempos, temas e tramas de pessoas/coisas em diálogo, e que expande desmedidamente a citada tendência político-comunicacional para a autorrepresentação. A montagem estética na tela do PC, Ipad etc. incorpora ubiquidade; atrai e expande a ótica transurbana. A relação sincrética e polifônica se instaura entre estas imagens e artistas outros que - no mesmo espaço-tempo e com outras linguagens - criam a metrópole. A montagem interna à tela do PC incorpora a ubiquidade; atrai e expande a ótica digital, desconecta o equilíbrio psíquico sacudindo-o com as turbulentas árias de pixel. Desloca a conclusão da pesquisa rumo a uma composição multissequencial para além da escrita etnográfica somente. 
Etnografia ubíqua significa que o novo sujeito formador da ubiquidade performática (que "desdefine" com uma linguagem visual ou estética - um codex-design - o sentido teórico e comportamental) não está na bibliografia acadêmica dos ideologues, mas sim entre os sujeitos ativos da criatividade: em primeiro lugar, alguns arquitetos que sentem o pulsar da mudança e o dirigem para composições inéditas. A já citada Zaha Hadid é uma dessas fontes. Ela é filósofa comunicacional que inventa os cenários presentes/futuros. É necessário saber interrogar as suas obras, observá-las e delas participar, dialogar com todos os detalhes expressos pelas suas formas, ler as suas entrevistas ou declarações de estilo, encaminhar sensibilidades óticas entre os contornos dessas obras que deixam interdita a respiração e despedaçam a ordem das frases. Tomo como exemplo o projeto, por ela idealizado, "Performing Arts Centre on Saadiyat Island" (Abu Dhabi), em que a estrutura se torna teatral, flexível e mutante como uma performance, uma arquiperformática: "a sculptural form that emerges from the linear interesection of pedestrian paths within the cultural district, gradually into a gorwing organismo that sprouts a network of successive branches" (LUECKE, 2011).

Os caminhos percorridos produzem cultura e se transformam em interseções em forma de rede orgânica, isto é, em meus termos, em um body-corpse que mistura o vivo e o morto, coisas e corpos, orgânico e inorgânico: brânquias abertas à respiração e à escuta:

As it winds through the site, the architecture increases in complexity, building up height and depth and achieving multiple summits in the body housing performance spaces, which spring from the structure like fruits on a vine and face westward, toward the water. (LUECKE, 2011)

O espaço se torna performático e o vento que atravessa o lugar atrai olhares afins, olhos que atravessam a escuta, que percebem a multiplicidade do som.

The concert hall is above the lower four theatres, allowing daylight into its interior and dramatic views of the sea and city skyline from the huge window behind the stage. Local lobbies for each theatre are orientated towards the sea to give each visitor a constant visual contact with their surroundings. (LUECKE, 2011) 
Releem-se as notas inesquecíveis de Nietzsche, quando ele descreve a filosofia arquitetônica do teatro grego, no qual o sujeito que assiste à tragédia sente com cada um dos seus sentidos abertos, dilatados ao estupor do panorama cósmico ao redor dele. E, ao redor, há a psique. A noção de teatro, portanto, não está encerrada em um espaço, selando os sentidos de espectadores obrigados a ver/escutar só aquilo que têm diante de si; o teatro instável torna-se performático na sua imanência visível e perceptiva quando assegura e liberta o olhar atônito de um observador participante do seu destino para o exterior que o circunda e o muda com o passar do tempo. O drama, portanto, une interno e externo, não o separa cirurgicamente, enterrando as sensibilidades atenuadas dentro do já visto. As artes e as ciências humanas desejam obras performativas. Uma etnografia performática direciona uma atenção ubíqua para essa filósofa e antropóloga da arquitetura artística que antecipa e elabora novas sensorialidades transurbanas. Ela é filósofa do contemporâneo que desdobra o presente-futuro, antes e melhor do que os clássicos autores citados para qualquer eventualidade. A filosofia está fora da filosofia, assim como a antropologia está fora da antropologia.

\section{D.A.R.}

Em tais cenários ubíquos, os avanços cibernéticos de Bateson podem se encontrar com as reflexões reproduzíveis de Benjamin. O insuperável storyteller das cidades se encontra - em uma montagem metodológica - com o mestre da ecologia da mente, do duplo vínculo, da metacomunicação fotográfica aplicada em vilarejos balineses. Como se sabe, Benjamin elabora uma das suas obras mais famosas sobre a potencialidade da reprodutibilidade técnica de entrar em conflito dialético com a aura, através da qual a classe operária e proletária pudesse desafiar as classes aristocrático-burguesas na experiência da experiência estética. Como a tecnologia é parte constitutiva da experiência artística, ela - tornando-se reproduzível - pode dar um impulso a uma reviravolta revolucionária na elaboração, produção e fruição das artes.

Sucessivamente, e com um itinerário totalmente autônomo, a arte de Andy Warhol enfrenta a serialidade de um modo diferente: tão afim à reprodutibilidade de Benjamin quanto diferente da massificação de Adorno. A pop art entra no corpo serial das mercadorias, seleciona os ícones mais "simbólicos" difundidos pelos mass media, os desloca e os esvazia do seu poder 
simbólico através da serialidade, reprodutibilidade, massificação. Warhol unifica Adorno e Benjamin finalmente sob o sinal feito por um dandismo lúdico e erótico. Entre os dois amigos frankfurtianos houve tensão política e teórica: Adorno respondeu ao ensaio de Benjamin com um livro sobre a reificação da escuta, em que mostrava um cenário em que as técnicas massificadas - em vez de libertação sob o signo da reprodutibilidade - aumentavam enormemente os processos de reificação. Tais visões divergentes da tecnologia e da cultura de massa não se resolveram jamais, por causa do seu sistema filosófico: a dialética hegeliano-marxiana. Graças ao fato de ignorar tal método, Warhol conseguiu não sintetizar, mas sincretizar na serialidade pop os dois amigos, desfazendo a dialética reproduzível/massificado. A sua arte esvazia o poder dos símbolos e - assimilando Mao, Marilyn e Campbell - neutraliza o seu poder político, sexuado, mercantilizado para difundi-los como signos impuros. Depois dele, aurático ou massificado não têm mais sentido.

Reprodutibilidade, massificação e serialização se cruzam, conflitam e se reproduzem com uma condição: a existência da cultura de massa da qual Warhol depende. Sem mass-media não existe pop art. A comunicação digital, no entanto, expande potencialidades compositivas autônomas das mídias, ou melhor, diferentes dos mass media. A internet subtrai o mass inicial das mídias, é um media para além das massas massificadas, reproduzíveis ou serializáveis: a web afirma "o media", uma mídia singular-plural que incorpora uma série de operacionalidades que antes eram diferenciadas e que agora se unificam em um instrumento único. Tal mídia singular-plural se conecta às potencialidades experienciais, emotivas, compositivas de subjetividade multividual.

Dos pixels dos mass media generalistas surge o conceito de Fake, que, já no cinema clássico, havia se apresentado como visão política outra: fake não significa falso (não verdadeiro), mas sim explora o para além do dualismo verdadeiro-falso. Se é próprio da arte escapar dessa armadilha dicotômica, certamente a arte do digital multiplica tal potencialidade. Orson Welles apresenta essa dissolução em um dos últimos filmes - F or Fake (1974) - em que as perspectivas de um fake-being auraticamente reproduzível expandido pelo digital configura uma identidade fluida para além da dicotomia falso-verdadeiro. O que conta é um cenário totalmente outro, que deveria ser o contexto de tal busca.

O cenário que está surgindo, cruzando cibernética e digital, oferece perspectivas inéditas diversas. Uma geração de 
artistas, designers, performers, arquitetos, sound-designers (cujos perímetros disciplinares são desafiados e atravessados) começa a moldar obras antes da produção-consumo dos mass media generalistas e uma vez hegemônicos. E então, em vez de oposição dialética e classista entre aura e reprodutibilidade, as articulações digitais misturam essas duas perspectivas que - de dicotômicas - se tornam sincréticas, polifônicas, diaspóricas. Surge uma comunicação aurática reproduzível que o digital dissolve para além do dualismo das tecnologias (e filosofias) analógicas. Todo traço inserido na web - seja ele musical, literário, artístico ou dentro de uma rede social pode permanecer na sua força expressiva "aurática" e/ou estar disponível a infinitas "reprodutibilidades" descentradas. Em vez de arte coletiva, são artistas conectivos que se afirmam. Daí a crise do copyright, que está se tornando elemento político-econômico, cultural-comunicacional, jurídico-tecnológico caracterizante do conflito contemporâneo estendido aos princípios clássicos da cidadania.

Nessa "aliança" entre Bateson e Benjamin, os mecanismos autocorretivos da cibernética transitam no digital e na web-comunicação, autorregulam os circuitos de transmissão das informações, levam para cenários de uma reprodutibilidade aurática digital, para além da dialética, das dinâmicas de classe, da lógica binária: D.A.R. Os processos liberacionistas não podem permanecer encerrados dentro de modelos de software que, enquadrando os sujeitos interconectados, reafirmam economias e valores tradicionais (CANEVACCI, 2012a).

Nesse sentido, os itinerários da indústria cultural - discutidos com paixão antecipada por Benjamin e Adorno e, depois, pela comunicação digital - favoreceram uma tendência insuspeita: a cultura digital cruza dimensão aurática e reprodutibilidade técnica. Em vez de um dualismo oposicionista entre aura burguesa e reprodutibilidade operária (entre reificação e igualação), o digital sincretiza reprodutibilidade e aura. Essa aura reproduzível - que é uma aporia para o pensamento dialético - expressa manifestações liberacionistas para uma comunicação digital da qual as composições etnograficamente dramatúrgicas são os resultados principais. De fato, esse mix decomposto e descentralizável e tecnologias e subjetividades torna qualquer produto visual tanto consumível virtualmente em todo lugar quanto potencialmente modificável.

A comunicação digital é, ao mesmo tempo, irreproduzível e reproduzível. E esse trânsito dissolve os laços com as classes sociais que Benjamin ainda identificava com certeza: bur- 
guês-aristocrática no primeiro caso; operária-proletária no segundo. Aquela força estética que se coagulava no conceito de aura - a desfrutabilidade da obra de arte em um tempo e em determinado contexto (o hic et nunc) - agora se enxerta entre as inovações digitais praticáveis na experiência de todo teenager glocal. O digital é auraticamente reproduzível. Esse potencial mix inovador - aurático-reproduzível - é um indicador decisivo para entender o que está mudando nas artes contemporâneas. É um salto paradigmático claro e expressivo com relação ao passado. De fato, a relação sociológica entre consumo e mídias analógicas dividia dicotomicamente os sujeitos sociais entre quem produzia e quem consumia: no primeiro caso, o trabalhador portador de política ou o artista isentado do trabalho; no segundo, o consumer assujeitado em uma passividade induzida pelo nivelamento homologante, pela indiferença dos significados.

Segue-se disso uma crescente alteração que vai dos mass media clássicos aos post-media contemporâneos, elevando o canto fúnebre para o primeiro: os mass-media estão morrendo porque o referente não é mais o conceito sociológico de massa, mas sim o conceito comunicacional de multivíduo. A comunicação digital post-media favorece o surgimento de uma subjetividade que não tem mais uma identidade estável, fixa, compacta baseada em um único trabalho, um único território, uma família eterna; mas sim identidades fluidas e mutantes feitas de "eus".

\section{Original-Fake}

Em uma edição que saiu durante minha permanência na China, do jornal South China Morning Post, tinha estampado um artigo com uma reflexão que me impressionou muito, estava escrito: a China transformou-se na fábrica do mundo e o Made-in-China está conquistando os mercados globais. Esta deve ser considerada a primeira fase da revolução que está mudando as relações entre os diferentes setores no mundo todo, mas que não pode continuar dessa maneira pelo seguinte motivo: uma grande quantidade de produtos aqui fabricados é o resultado de patentes ou de qualquer maneira de invenções que provém do estrangeiro, como Europa, Estados Unidos e Japão. Esta fase de produção em pátria de produtos inventados em outro lugar deve ser superada com a finalidade de concentrar recursos, tecnologias e pesquisas frente a inovações. $\mathrm{O}$ design, por isso, deve tornar-se o centro dos investimentos da 
fase dois, compreendendo por design a arquitetura, o projeto, a criação e a patente. A China não poderá ficar por muito tempo nesta zona ambígua onde o Made-in-China muitas vezes é acompanhado por etiquetas do tipo: "Projetado pela Apple na Califórnia, Montado na China".

A China não deverá mais ser o local de montagem de tecnologias e projetos concebidos no estrangeiro, por isso - essa era a conclusão do artigo - o desafio do presente é Design-in-China. Por isso, "pequenas" cidades como Wuxi, financiaram projetos de escala global para atrair algumas centenas de designers também estrangeiros e iniciar uma atividade de formação destinada à criatividade local, atitude bem entendida por Robin Li, inventor do mecanismo de busca Baidu, e por isso escolhido pela revista Time como uma das cem personalidades mais influentes do mundo.

Amplitude e imaginação: estas duas coordenadas, uma espacial e outra mental, definem a nova fase da China e por isso foram escolhidas como palavras chave pela Expo de Xangai.

As muitas pessoas que ao mesmo tempo adquiriram mercadorias chinesas exportadas em quase todos os cantos do planeta tinham a clara visão de que estes produtos pareciam verdadeiros, é como se fossem verdadeiros, talvez até sejam verdadeiros. O dualismo "Verdades e Mentiras" não é capaz de compreender a profunda mudança "superficial" dessas coisas. $\mathrm{Na}$ verdade, elas muitas vezes são produzidas na China sob licença das grandes marcas, por exemplo, italianas, no que diz respeito às roupas, só que é suficiente modificar uma letra (de Armani a Amani) para evitar improváveis causas, mesmo que o produto seja de todo igual ou verossímil. Saem muitas vezes das fábricas ou das subfábricas, fantasmas, gêmeas ou paralelas sem que sejam nem mesmo necessárias operações camuflagem. Resumindo, os direitos autorais (copyright) estão em crise não só pelos produtos intelectuais, como se diz obsessivamente nos convênios e nos parlamentos, mas também nos produtos materiais. Para melhor representar o meu pensamento, esta distinção entre material e imaterial não funciona mais, é um dualismo lógico - e produtivo - em crise, que tenta defender um passado claramente limitado e certamente alterado. De qualquer maneira, nenhum governo procura imobilizar estas inovações tecnológicas que podem replicar as "coisas" com apenas o toque de um botão, nem sequer as empresas que produzem estas tecnologias de reprodutibilidade sofrem crise moral ou denúncias penais, aliás, estamos vivendo uma fase na qual todos nós podemos seja criar coisas, histórias, imagens, seja 
replicar-lhes sem dever por isso pedir permissão a ninguém; e os anúncios contra as assim chamadas "piratarias" parecem favorecer os piratas e causar risada na platéia.

O copy-left não é só um slogan de uma esquerda liberal e pirata, é a prática que qualquer pessoa dotada de instrumentos, agora ao alcance das mãos, realiza na vida cotidiana, só que essa atividade reprodutiva na China envolve ambos os lados, dos produtos e da inteligência de uma maneira extensa na amplitude e na imaginação. E assim, uma vez que a autenticidade do produto é cada vez menor, com essa, o valor ambíguo que tal conceito sempre comportou: o ser autêntico é realmente uma ideologia ou um absurdo modelo restaurativo. Em antropologia, portanto, a autenticidade juntamente com a pureza e a origem foram questionadas há muito tempo, estão em discussão como culturas e até mesmo os indivíduos não podem mais declarar-se, ou pior, serem declarados autênticos, puros, originais: mas sim, são um resultado de misturas complexas, híbridos e mutações, uma vez que alguém - estilista de moda ou engenheiro de software - invente um produto, este se torna uma cidadela circundada de olhos que farão qualquer coisa - se possuí um appeal - para copiá-la. É uma espécie de canibalismo-techno que é posto em movimento. As coisas vêm selecionadas, dissecadas, engolidas, montadas e recicladas como se fossem deliciosas partes de um corpo inimigo feito prisioneiro e cozinhado, ainda cheio das virtudes que trazia consigo e cujo objetivo final será o de ser devorado e absorvido da famosa iniciativa local.

Este canibalismo-techno, um devorar de produtos e tecnologias para tomá-las como sua fisiologia individual, caracteriza certamente não só a China, mas em prática todos nós. Na verdade a China conseguiu dar em pouquíssimo tempo um salto organizado, diria quase sistêmico, a tudo isso, unificando reprodução material e imaterial, além das lojas "oficiais" (um termo obsoleto), nos mais diversos territórios se expandem lojinhas, bancas e banquinhas, carrinhos, simples tapetes, ambulantes e assim por diante: uma infinita e uma microfísica incontrolável de venda cujos custos de reprodução são aproximadamente zero e os preços de venda sem possibilidade de concorrência com produtos similares de outras partes do mundo, ou seja, a China interpreta melhor aquilo que a fase atual glocalizada oferece graças ao modo tempo-espaço acelerados com a tecnologia digital. O clássico conflito entre as forças produtivas e as relações de produção é antigo, não são mais importantes. 
O atual conflito é entre as forças produtivas e ideacionais tecnologias reprodutivas. O motor central é sempre a concepção inovadora, só que essa aura dura só um nano-segundo, porque sua exposição é oferecida aos olhos de todos os replicantes. A aura é reprodutível. O melhor exemplo é o desfile de moda: se organiza um evento para apresentar os modelos com roupas novas, uma vez que o estilista deve mostrar a coleção de temporada e o desfile não pode não ser global, porque global é o produto e a marca. No mesmo momento que põe em movimento um mecanismo impossível de ser interrompido, porque é o mesmo evento que o aciona: o copy-left do canibalismo-techno. Um software recém desenvolvido não tem um destino muito diferente: as defesas para protegê-lo são constantemente atacadas pelas mesmas "lógicas" que o reproduziram. Esta difusão irresistível do fake não acontece apenas na reprodução de bens e cultura, mas também na mais sutil e vintage esfera do consumo, ainda mais claramente neste plano, o Fake deixa de ser o oposto de real ou autêntico: é a onda que acelera a mudança de estilos de vida e que propaga uma simples verdade sobre o estado das coisas. Fake é o verdadeiro-falso, uma mistura enorme que dissolve as distinções de dualidade inerente do clássico baseado na certeza da verdade. A arte nunca é realista e nem reproduz a realidade. A arte expressa dissonâncias para cada artista e realismo. A expansão do fake no consumo e na comunicação urbana exige um processo semelhante ao de reprodução, em que cada pessoa se torna performer, que o conceito em seu "ativismo" é mais preciso que prosumer. Esta ambiguidade verdadeiro-falsa se expande a vários domínios da vida urbana, como o que conheci em minha viagem. Essas experiências do tema-parque (theme-park) estão se tornando não apenas ligadas a lugares específicos e locais de lazer (loisir), onde se paga um bilhete para entrar, são colocados em áreas que fazem parte da vida cotidiana, quando se sai e se entra sem um limite formal ou simbólico, um limen avisa o fim de uma fase conhecida e o início de outra ainda desconhecida - o entretenimento. Assim, os "piratas" da metrópole inesgotável de mais de trinta milhões de habitantes em Chongqing, não são os primeiros e ainda menos os últimos:

Hans-Jörg Kaiser, an Austrian representative on the International Council on Monuments and Sites, which advises UNESCO on heritage preservation, said Halstatt residents 
were quite upset that their homes were being secretly cloned half a world away (PLATT, 2012).

Qual é a diferença entre Armani e Zaha Hadid fake?

Fake-in-China está entre o made e o design, entre a fabricação de produtos alheios e a criação de um desenho próprio. Aquelas que ainda chamamos fábricas em parte tornaram-se qualquer outra coisa, assim como as empresas de fabricação avançadas tendem a fazer coincidir o alvo com uma única pessoa, simetricamente se afirma o modelo do one-man-show na produção, isto é, a atividade com base no desempenho individual têm se expandido do espetáculo à reprodução dos produtos, até a sua revenda. O one-man-show é o segredo de vitória da China, o país mais individualista que existe na terra, e na qual o excesso de iniciativa reprodutiva tenta incentivar e, juntos, num quadro de visão de mundo determinada pelo destino, onde a tradição filosófica confucionista é adicionada e misturada à ideologia de Estado. Mas, para quê? Em certo sentido, of fake pratica uma obra de arte estendida aos produtos materiais e imateriais, ao consumo performático, à comunicação digital. E assim, o Fake está se tornando algo mais e alterado, uma visão de mundo com uma sua filosofia e tantas práticas estéticas.

\section{Metropóle Performática}

A metrópole comunicacional - diferente da cidade moderna e das metrópoles industriais - se caracteriza pelas relações entre a expansão digital cruzada com o tríptico comunicação-cultura-consumo. Este encontro produz seja valor econômico agregado e seja valores como estilos de vida, visão do mundo, crenças, mitologias. A comunicação é elemento sempre mais determinante à configuração flutuante de tal metrópole, respeito a qual o conceito histórico de sociedade perde a sua centralidade de enquadrar mutações, inovações, conflitos, tensões. Tal metrópole oferece um panorama ambíguo e auroral potencialmente além de dualismos metafísicos, paradigmas industrialistas, dialéticas sociológicas. A metrópole comunicacional não tem um centro politicamente definido, mas uma constelação policêntrica diferenciada temporariamente desenhada. Policentrismo significa que consumo-comunicação-cultura têm agora uma importância crescente em relação a produção clássica. Este encontro - baseado sobre shopping- 
-centers, parques temáticos, museu de arte, exposição universais, desfile de moda, estádios esportivos e, obviamente, internet - desenvolve um tipo de público que não é mais o público homogêneo e massificado da era industrial. São públicos pluralizado e fragmentados: públicos que gostam de performar consumo e comunicação.

Se favorecem projetos da parte de pessoas singular, de grupos informais ou de cidadão organizados que podem criar ficções poético-políticas aplicáveis entre conexões web-urbanas, aumentando informações temporárias, contos parciais, som interativos, imagens assembladas. A expansão de tais sensores conceituais quase invisíveis solicitam - "desejam" - ser individuados, leitos, observados, modificados numa pragmática horizontal. Isto é, política. Tais códigos labirínticos criam vínculos enigmáticos, distorções sensoriais, encontros casuais, montagens inacabadas. Dilata-se fragmentos narrativos material-imaterial que transformam a configuração urbana através de significados em movimento. Estendem-se subjetividades autônomas que escolhem narrar visões imaginarias através sua consciência ativa. Um fazer-se ver que é - no espaço/tempo ubíquo - um fazer-se metrópole: metrópole comunicacional, metrópole performática, metrópole ubíqua. Uma metrópole que narra e se narra vira reflexiva. Exprimem-se textualidades móveis, processuais, descentradas, autônomas, sincréticas, ubíquas. A comunicação digital produz "narrações aumentadas" que redesenham labirintos temporários nos quais se assemblam tratos compositivos colados nos interstícios urbanos. As raízes (roots) se movem da danação de ficar imóveis e fixadas no subsolo, pra virar itinerários luminosos (routes). Veredas e narrações interligam-se segundo lógicas impuras, pelas quais as metrópoles no fundo sempre se nutriram contra a "cidade ideal”, idealizada pelos filósofos, políticos ou urbanistas. Um ângulo de uma rua vira uma sequência visual, obra de arte pública. Labirintos com muitas saídas possíveis. Labirintos que não fecham, mas dilatam. Atratores de rua, metamorfoses simultâneas, sugestões de encontros, desejos deambulantes de perder-se. Panoramas improvisos emergem aumentando cidades conectadas entre elas. Plot de espaços.

A comunicação digital é ainda mais importante pelo aspecto de continuas inovações tecno-culturais, de valores comportamentais, linguagens mixadas (oral, icônico, escrito, sônico), relações identitárias. E a cultura - no sentido antropológico que inclui estilos de vida, visões do mundo, mitos etc. - é parte constitutiva da metrópole performática. 
Na perspectiva etnográfica aplicada na metrópole contemporânea, a performance está localizada no cruzamento transitivo entre autorrepresentaçao, ubiquidade subjetiva, mudanças estéticas. Comportamentos performáticos espontâneos, programados ou simplesmente solicitados estão se difundindo nos diversos espaços urbanos, segundo modalidades diversificadas e apresentando uma crescente intriga de público/privado. Aqui se cruzam arte pública, street art, grafite, pichações, publicidade, adbuster, bodyart etc. Simetricamente a comunicação digital expande um sujeito glocal que exprime autônomias criativas e horizontais desejos de expressividade: uma composição "política” de autorrepresentação, metrópole comunicacional e culturas digitais. A pesquisa etnográfica seleciona cenários intersticiais mesclados a serem penetrados com a mesma seriedade crítica com que Marx analisava fábrica, trabalho, valor. Tais cenários são compreensíveis nas conexões polifônicas, sincréticas, dissonantes entre cultura digital e metrópole comunicacional, que informam códigos, estilos, lógicas, identidades e até políticas bem além da simples tecnologia ou arquitetura. $\mathrm{O}$ sujeito que atravessa identidades temporárias, flutuantes, híbridas, incorpora o conceito de "multivíduo" ou sujeito diaspórico.

Autorrepresentaçao, metrópole comunicacional, arte pública, cultura digital, sujeito transurbano são os cenários inquietos e intercambiáveis aos quais dirigir o olhar etnográfico cada vez mais caracterizado pela ubiquidade: a etnografia ubíqua emerge do contexto e do método, mistura espaços-tempos, envolve toda a sensorialidade do pesquisador flutuante num fieldwork ubíquo material/imaterial. Para tal fim, o conceito de composição, filtra, fragmenta e combina os dados, os apresenta (os “compõe") através de uma diversificação de linguagens para dar uma compreensão parcial a um "objeto" de pesquisa que cada vez mais seapresenta como sujeito: uma mescla in between sujeito/objeto. O sujeito se expande no objeto como o material no imaterial e vice-versa: não existe dialética em tal processo muito menos síntese. Só fragmentos combinados ("co-penetrados") temporariamente de acordo com contextos empíricos e experiências individuais. A expansão das tecnologias digitais não pode ser interpretada como próteses do corpo humano, mas são co-penetrações contínuas e misturas híbridas no curso das quais nem sempre é definível onde começa o objeto (um mouse, a tela, o teclado) e o sujeito (os dedos, os olhos, o corpo/mente). O tecno-corpo digital favorece as hibridações entre mouse, mão, diferentemente das próteses analógicas pelas 
quais o martelo se acrescenta à mão. Nesse sentido, o mouse não é uma prótese que se adiciona ao corpo: é um corpo-mente (mindfull body) que incorpora e se sincretiza com este spray. $\hat{E}$ o corpo "eXpandido".

Na experiência transurbana (MUDLER, 2002), a questão-indivíduo está presente segundo modelos diversos nas culturas pós-industriais, que muitas vezes as ciências humanas eliminaram em favor do "comunitário" ou do "tribal". Há modelos diversificados de entender, viver e definir tal conceito nos diversos contextos histórico-culturais. $\mathrm{O}$ mesmo vale para o conceito de comunidade que - além do mais tem tradições nefastas na Europa que vão de Toennies ao nazismo (volksgemeinschaft) - continua ressurgindo em todo os partidos/ igrejas conservadores. Embora as relações entre aldeia e metrópole sejam muito mais complexas do que no passado, os trânsitos de códigos, estilos, até rituais são uma característica das mais diversas culturas. $\mathrm{O}$ que não leva à homologação, como durante muito tempo se sustentou, ao contrário, a pesquisa etnográfica ubíqua foi treinada para entender as diferenças como significativas e específicas de cada cultura, de cada estrato, classe ou grupo social e até de cada sujeito que participa cada vez mais in between fragmentos de culturas diferentes que junta temporariamente. A hipótese que levantamos é a de que arte pública e metrópole performática não são difundidas pela suposta homologação: pelo contrario, elas determinam a co-criação da metrópole contemporânea, flutuando entre estilos globais e reinvenções locais.

Linguagens icônicas, espaços intersticiais, conexões transurbanas, histórias biográficas, até atores/atrizes estão irremediavelmente modificados nas experimentações "eXterminadas" - que nunca terminam - nas artes vagas e vagante da ubiquidade transurbana. Os atos performáticos - codificados ou espontâneos - podem ser o desafio que percorre as trilhas web-urbanas, atravessando, cruzando e misturando fronteiras, culturas, subjetividades. A etnografia compõe suas pesquisas assumindo as linguagens performáticas como adequadas ao fieldwork e apresentando-as nas forças imanentes das composições (GOLDBERG, 2006). A etnografia indisciplinada incorpora o projeto performático nas suas narrações transitivas, polifônicas e diaspóricas, cruzando continentes diversificados e interligados na comunicação icônica transmedial. A etnografia ubíqua vive a experiência subjetiva de percorrer e ser percorrida por códigos outros, familiares $e$ estrangeiros, observados com um olho estranhado e outro ensimesmado que confun- 
dem etnógrafo, performer, espectador. E assim tal método etnográfico salta entre imersão programática e refletividade distanciada, racionalidades inter-subjetivas e emoções furiosas, escritura estranhada e composição mix-midial, comunicação aurática nas ruas e tecnologia reprodutível nas telas.

\section{Carpe a auto-representação}

O poeta romano Horazio falava sobre carpe diem, isto é, uma capacidade sensível de entender a beleza volátil de um momento vital que não é determinado pelo tempo cronológico, Kronos, que é colocado no calendário e subdivido regularmente em frações pra controlar a vida política e individual. Para os Gregos, existe um tempo diverso - Kairós - que precisa de ser vivido intensamente quando chega e, se chega, precisa de aferrar a ocasião na frente, quando rápida se apresenta nos movimentos assimétricos dos cabelos e por que atrás é careca. Esta divindade filosófica se pode relacionar aos códigos digitais que precisam de ser agarrados na frente hic et nunc e modifica-los. Kairós se incorpora nestas "narrações aumentadas", se insere numa antropologia indisciplinada através de tensão polifônica, dialógica sincrética, conflito comunicacional entre hetero e auto-representação. Os procedimentos etnográficos segundo os quais tradicionalmente o antropólogo(a) representava o outro com suas lógicas externas, com escritas e fotografias alheias, com as suas autoridades discutíveis foram - senão exauridas - ao menos atenuadas. Este trânsito está acontecendo seja sob impulsos pós-coloniais, seja graças à afirmação, mesmo que minoritária, de uma nova antropologia crítica além do monologismo imperante. Em consequência disto, parece evidente que "quem tem o poder de representar quem" está se tornando um nó central que se emaranha no domínio do "científico" que uma parte majoritária do Ocidente continua a exercer em direção e contra o outro externo e interno.

Uma nova crítica sobre o poder da representação posiciona-se entre um impulso externo pós-colonial e um interno sobre a autoridade representação; focaliza quem entrou na autonomia construtiva do próprio eu do qual tinha sido excluído como subalterno, colocando em discussão as modalidades clássicas desta mesma representação. A questão "de-quem-representa-quem" em todas as dobras do poder retoma e amplia a crítica sobre a divisão do trabalho assim como Marx a tinha representado, tornando insuficientes as leituras dos séculos 
XIX e XX, baseadas na centralidade estrutural de estratificação social e processos produtivos. A atual fase pós-industrial e a aceleração das culturas digitais incluem outras "divisões" entre sujeitos pertencentes a culturas e experiências diversas: por exemplo, a divisão entre quem comunica e quem é "comunicado", entre quem tem historicamente o poder de narrar e quem está apenas na condição de ser um objeto narrado.

Por isso entre "quem representa" e "quem é representado" há um nó linguístico específico, relativo ao que chamo divisão comunicacional do trabalho, que precisa ser enfrentada nos métodos e nas pragmáticas. Entre quem tem o poder de enquadrar o outro e quem deveria continuar a ser enquadrado se ossificou uma hierarquia da visão que é parte de uma lógica dominante a ser posta em crise na sua presumida objetividade. É insuportável que na comunicação digital proponha-se um neo-colonialismo midial com uma divisão hierárquica entre quem representa e quem é representado, entre quem filma e quem é filmado, quem narra e quem é narrado, quem enquadra e quem é enquadrado (CANEVACCI, 2012b).

As novas subjetividades estão praticando a facilidade de uso do PC ou do Ipad, descentralização ideação icônicas nas ruas ou editing digitais em casa. A divisão comunicacional do trabalho entre quem narra e quem é narrado, quem performa e quem é performado - entre auto e hetero-representação penetra na contradição emergente entre produção das tecnologias digitais e uso destas mesmas tecnologias por sujeitos com uma autônoma visão do mundo; e entre o controle vídeo do espaço público e o decontrole cotidiano desta alteridade interna. Tal divisão e tal contradição redefinem o cenário do poder no qual a antropologia da comunicação se dispõe para conflitar contra toda persistente tentativa folclorizar o outro. $\mathrm{O}$ pesquisador externo não tem mais o direito de afirmar-se absoluto, precisa de posicionar-se numa definida parcialidade processual que favoreça a autonomia narrativa do outro por renovar as metodologias ossificadas (veja-se o persistente revival do termo "tribal"), como as relações de poder baseadas em lógicas coloniais.

A autorrepresentação afirma modos plurais através dos quais os que foram considerados por muito tempo apenas objetos de estudo revelam-se sujeitos que interpretam em primeiro lugar a si mesmos e depois também a cultura da metrópole. Os novos códigos expressivos através dos quais podem ser narradas a cultura ou a subjetividade de cada grupo 
humano não estão mais centrados num saber objetivo restrito a um saber tecno-científico e icônico-expresivo: ainda hoje as lógicas museais através das quais se expõem os "nativos" ou os "urbanos" são expressões de uma tentativa autoritária ou paternalista de englobar o "outro.

As heterossubjetividades da comunicação visual atravessam novos processos narrativos que colocam a autorrepresentação em cenários móveis, também de uso cotidiano, no qual as imagens urbanas viajam em todas as direções. Estas representações plurais inovam e cruzam a comunicação urbana e digital, justamente porque são compostas por sujeitos que refletem de dentro das suas culturas segundo modalidades performativas e processuais. Sincretismos culturais, pluralidades de sujeitos, polifonias de linguagens: esta é a premissa metodológica da metrópole performática transurbana. Tatuagens são street art, corpo de um sujeito, corpo de um muro e corpo de um site dialogam e se cruzam entre eles, mas não se unificam...

Um salto compositivo e metodológico transborda numa perspectiva diferente de sentido aplicável à heterorrepresentação a partir do conceito de "hetero-nomia", fazendo deflagrar a sua dependência do outro oposto como "auto-nomia". Heteronímia pode se tornar visão que altera o nomos, transformando-o - de regra estabelecida ou lei imperscrutável em módulos flexíveis, sensíveis por alteridade que normalmente são excluídas ou reprimidas pelo sujeito autônomo. Os direitos de autonomia se baseiam num conceito de cidadania que não funciona mais há tempo especialmente na base dos processos de globalização. Se é o cidadão a ser autônomo, o outro - migrante, viajante, apátrida, exilado, estrangeiro ou estranho - é excluído dos seus direitos (nomos). E quem é "cidadão" na metrópole comunicacional?

Heteronímia antecipa o nickname. Então significa inserir, atrair no seu conceito mudado a alteridade como irrecondutível num sistema de códigos dados; tornar mutável o nomos nas multiplicidades do outro. Transformar-se em heterônomos significa entrar no desafio que um poeta como Fernando Pessoa lançou nas suas escrituras. Pessoa (nomen homen) usa heterônomos não só pelo gosto de mudar de nome e identidade, como para dar sentido a estilos de escritura diferentes, como para sentir próxima, muito próxima a relação entre o próprio único nome - pessoa única - a identidade uma e um estilo coerente de escritura ou, para permanecer nos meus termos, entre representação e composição. 
Experenciar a ubiquidade transurbana e transmedial apresenta um primeiro posicionamento que poderia ampliar ou aumentar a perspectiva da auto-representação: mudar o inicial carpe diem para carpe codex: agarrar os códigos e transforma-los....Os códigos são sempre mais móveis e sincréticos e parecem que esperam somente o sujeito multividual que exercita o prazer de experimentar o que ainda não foi comunicado.

\section{Três pílulas metodológicas}

As metodologias que se poderiam aplicar na comunicação artística expandida performaticamente são plurais: é impossível aplicar uma metodologia só adaptada por uma singular manifestação. Por isso, queria apresentar algumas breves perspectivas metodológicas que reciprocamente influenciam-se.

Etnografia é reflexiva. Em primeiro lugar, o pesquisador que quer enfrentar este âmbito através os métodos etnográficos precisa de se colocar numa dimensão reflexiva.. Isso significa que ele(a) não pode imaginar de ficar neutral, objetivo, distante em relação ao objeto de pesquisa ou do prazer estético que sempre mais se apresenta como sujeito. Pelo contrario, a sua emotividade é envolvida no olhar, a sua sensibilidade, a sua percepção sensorial. O pesquisador reflete sobre si mesmo na medida em quem analisa (e é analisado) o objeto-sujeito. Precisa saber escutar-se e dialogar consigo mesmo.

Estupor metodológico. Treinar-se no estupor é determinado pela mistura flexível do familiar e estrangeiro, que antes era claramente uma oposição binária e dialética. O museu transitivo é sempre mais familiar/estrangeiro. O exótico faz tempo é parte da experiência cotidiana de cada cidadão. Não está mais em um lugar cognitivo diferente ou bizarro do consumidor: escolher comunicar uma diferença exotizada é só uma questão de estilo. Este treino baseado no estupor compõe a porosidade corporal em relação a um potencial encontro com pessoas/culturas/obras desconhecidas ou estranhas e que justamente por isso são desejadas. Os pesquisadores precisam colocar a própria inteligência sensível no liminar ambíguo do estupor: assim é possível penetrar e ser penetrado pelo que é estranho enquanto é inovador, sem fechar-se na sua própria normalidade fixa; a metodologia do estupor é básica e se conecta com o ponto seguinte.

Fetichismo metodológico. Uma abordagem das formas comunicacionais das coisas animadas que dissolve o caráter reficado da mercadoria através do deslizamento semiótico 
dos códigos nelas incorporadas. A interpretação é, ao mesmo tempo, uma destruição dos estereótipos heterorreproduzidos. O fetichismo metodológico é, por assim dizer, homeopático: ele tira os estereótipos fetichizados, exasperando e dilatando as construções interpretativas encenadas pelas próprias coisas-mercadorias, ao longo de sua vida comunicativa. Olhar eróptico: um mix de óptica e erótica por treinar a refletividade do pesquisador a "fazer-se-olho" durante seja no fieldwork, seja na composição final; erótica é uma sensibilidade conceitual que dilata a pupila em direção da sensualidade perigosamente sedutora e deslocante; o olhar do pesquisador é desafiado; este mesmo olhar precisa virar oblíquo mais que frontal. E aprender a se olhar enquanto olha. Fazer-se ver. Para desenvolver o ponto de vista da observação reflexiva é preciso colocar-se nesta pró-posição. Uma posição sensível não tanto à semiótica, à estética, à comunicação, quanto ao ato "passivo" de ver. Fazer-se ver: não no sentido de aparecer, mas nos variados sentidos de desenvolver qualidades sensitivas fundadas nas percepções do olhar, na sensibilidade do ver, do mudar-se em ver, em coisa-que-vê e se vê. Tornar se olhar, um corpo cheio de olhos. E de bonecas....

\section{Final: manequim performática}

Confesso que - por culpa da minha tendência fetichista - sou um colecionador de manequim, infelizemente ou por enquanto só de fotos, mas queria imaginar uma exposição de arte transumana só de bonecas, onde elas se auto e hetero-representam. Esta breve seleção talvez consiga esclarecer o sentido de uma arte vaga - espontânea e expandida - que cria um design performático nos panoramas metropolitanos. As ruas são potencialidade de "objeitos" expositivos que claramente são também sujeitos performáticos. É um tipo espontâneo e casual de criatividade que anônimos comerciantes colocam nas ruas. Ou que talvez elas mesmas construam na própria irredutível autonomia performática.

Encontrei a primeira (a preferida) numa praçinha de Belém (no Pará), onde uma feira popular apresentava produtos. Fiquei subitamente apaixonado por este manequim pelas suas formas estranhas e pela tristeza infinita do seu olhar: em primeiro lugar, o corpo cor de laranja me impresionou, nunca vi este tipo de cor humana representado por uma boneca. Depois faltava um braço. Olhando bem, o pescoço era quebrado e torto. Totalmente careca, ela tinha uma expressão bem triste 


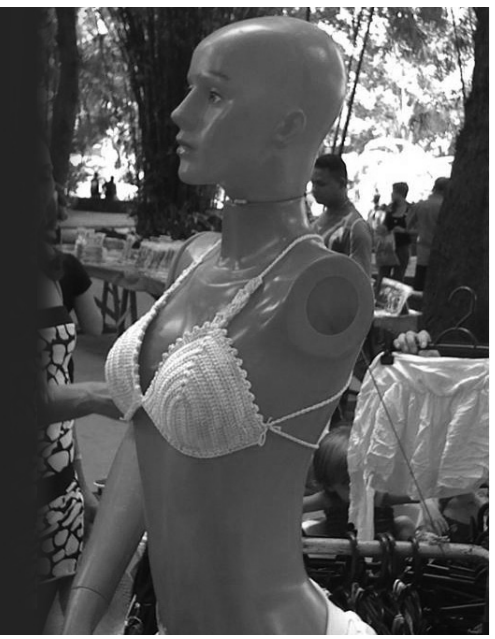

Figura 1 Belem

Figura 2 Recife

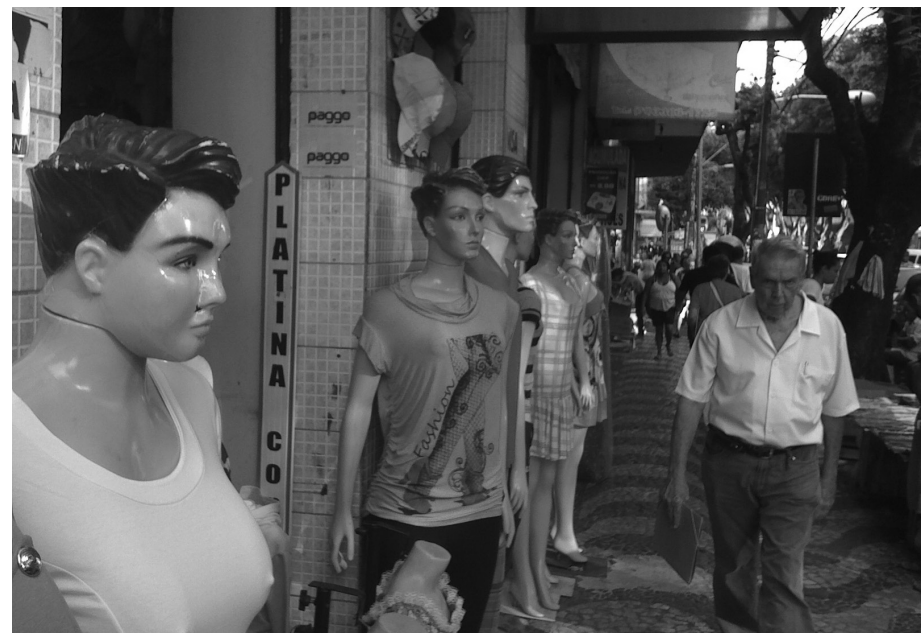

no rosto e especificamente nos olhos, como se alguma coisa terríve houvesse acontecido em sua vida. Quem sabe quantas histórias desde seu nascimento na China, Fake-in-China, a viagem clandestina e sem passaporte, a dura seleção para trabalhar no Brasil. Não consegui perguntar-lhe nada, por que seu patrão estava perto para controlar se tudo estava certo. De novo me perguntei o por quê da sua face triste e, apesar de ter um corpo assim desastrado, imaginei que a causa principal era aquele sutiã bem feio que era constrangida a endossar naquela praçinha. Uma construção ofendida de um regime trabalhista autoritário. Tinha a fantasia de comprá-la, de liberar a boneca e levá-la comigo para São Paulo. Mas tive medo e a minha hipocrisia ganhou, imaginei de não conseguir de enfrentar os olhares maliciosos dos passageiros. Eu fetichista e ela silenciosa. E assim a fotografei. A fotografei muito. Coloquei a sua imagem do lado da minha escrivania e assim continuo a olhar para ela enquanto escrevo, com uma saudade inesplicável. Minha amante desarticulada...

A segunda imagem é de Salvador (Bahia). Perto do Campo Grande, a rua XI de Setembro se abre a uma multidão de lojas e lojinhas sempre teatrais. De novo fiquei atraído pelas marchas das manequins em direção da calçada, como fosse insuportável para elas ficarem paradas no interior da loja. E aquele homem que caminhava solitário, quase fechado em si mesmo, no instantâneo da foto, assim parado como elas. Imaginei que ele também era um boneco, como eu, que desejava parar na frente daquela deliciosa boneca, aquela em 


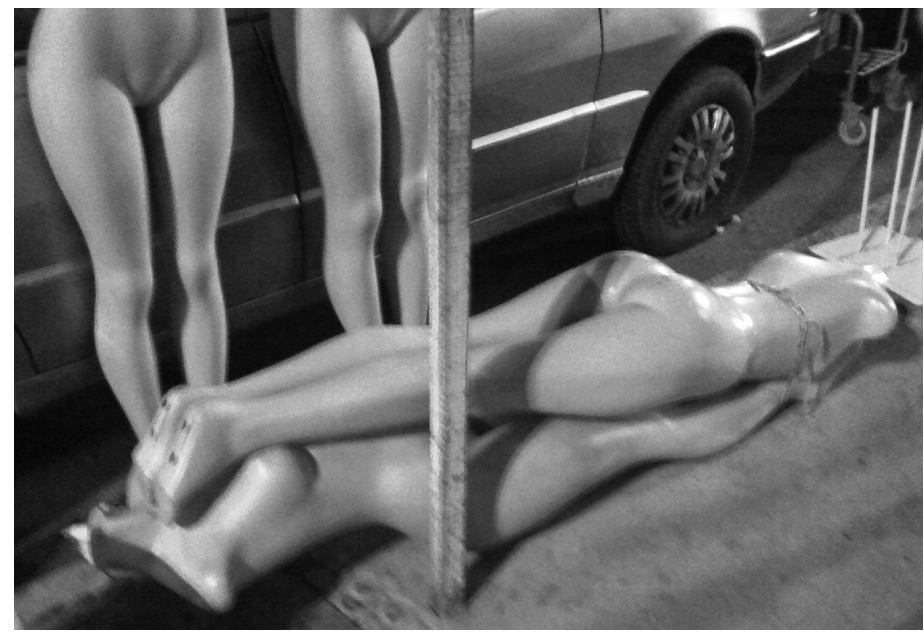

primeiro plano, que parece distraída mas claramente está esperando ele que passe na sua frente. Em Salvador, a invasão das manequins viventes, manequins Fake-in-China, já iniciou e os híbridos, metade bonecas e metade humanos, já estão povoando não só o estado de Bahia. Me lembrei de um filme famoso, quase um Cult, Invasion of Body Snatchers de Don Siegel, e imaginei que a situação é fora do controle. Bonequizaçao dos humanos está acontecendo.

A terceira foi capturada a Recife, de novo numa praça bem grande onde uma feira popular para turistas oferece os produtos artesanais. De noite, quando os comerciantes começam retirar seus produtos, descobri e assustei-me com a visão de uma situação anômala. Na ruazinha lateral, uma multidão de manequins esperavam para tomar a van para ir descansar. Só que na calçada descobri duas bonecas já abraçadas numa intimidade ao limite da censura. Talvez capturadas por um raptus erótico, elas pareciam namorar, uma reclinada sobre o corpo da outra numa inequívoca posição sexual, enquanto as outras amigas em pé assistiam indiferentes ao encontro amoroso ou talvez como voyeurs interessadas. Os corpos nus, de uma cor ambígua, lúcidos e suados, declaravam sem dúvida que a paixão dos humanos pelas bonecas mais ou menos confiáveis era em competição com a atração bem sedimentada entre as mesmas manequim. las se adornam por que entenderam que esta paixão é a mesma dos humanos. É além dos humanos...

Enfim, a ambiguidade da presença de bonecas nas ruas e a crescente proliferação deste seres nas lojas sem dúvida 
manifesta a vontade sexuada de apresentar formas mais ou menos espontâneas de performance que atiram os olhares cruzados das mesmas bonecas e dos humanos. A exposição destas manequins-bonecas ou fantoches-marionetes é um desafio disseminado nas ruas que um fetichismo perturbativo oferece e pelo qual eu sou extremamente sensível. Talvez o sentido de um museu de arte sempre foi criar sustos através exemplares bonequizados para representar o "outro". Agora a revolta de bonecas nas ruas aparece como crítica da estética clássica, assim se cria uma nova visão crítica: elas penetram os olhos e bloqueiam a pupila seja do pesquisador e seja do visitantes. A revolta é uma sedução.

\section{Referências}

(b) Linha de pó. A cultura Bororó entre mutação e auto-representação. São Paulo: Annablume, 2012.

BAKHTIN, M. L'autore e l'eroe. Torino: Einaudi, 1988.

CANEVACCI, M. (a) Digital Auratic Reproducibility: Ubiquitous Ethnographies and Communicational Metropolis. In NAIDOO, Loshini (org). An Ethnography of Global Landscapes and Corridors. New York: InTech Publisher, 2012.

GOLDBERG, R. A Arte da Performance. São Paulo: Martins Fortes, 2006.

LUECKE, S. 2011. Performing Arts Centre Abu Dhabi by Zaha Hadid. In Design Magazine for Middle West and North Africa. Disponível em < http://desmena.com/? $\mathrm{p}=49=1>$. Acesso em 15/12/ 2012

MARINETTI, F.T. Manifesto del Futurismo. In Teoria e invenzione futurista. Milano: Mondadori, 1968, pp. 7-13.

MUDLER, A. Transurbanism, Rotterdam: V2_Publishing, 2002

PLATT, K.H. Copycat Architects in China Take Aim at the Stars. In Spiegel on Line. Disponível em < http://www. spiegel.de/international/zeitgeist/pirated-copy-of-designby-star-architect-hadid-being-built-in-china-a-87439o. html>. Acesso em 28/12/2012

SOBCHACK,V. Meta-morphing. Minneapoli: University of Minnesota Press, 2000.

NOTAS

1. No "Il manifesto Futurista", Filippo Tommaso Marinetti (1968) explica a força sedutora da metrópole e da simultaneidade que se expande nas 
obras de arte. No quadro "La città che sale" (a cidade que sobe) de Umberto Boccioni, podemos ver aplicado na pintura um pulsar urbano, fonte de inspiração para leituras da metropole contemporânea.

Recebido em: 03/04/2013

Aceito em: 03/04/2013

\section{MASSIMO CANEVACCI}

maxx.canevacci@gmail.com

É professor de Antropologia Cultural e de Arte e Culturas Digitais na Faculdade de Ciências da Comunicação, Universidade de Roma "La Sapienza". Desde 1984 ensina e faz pesquisa também no Brasil. Pela pesquisas sobre São Paulo, recebeu em 1995 do Governo Federal Brasileiro a "Ordem Nacional do Cruzeiro do Sul". Como professor visitante atuou em diversas universidades europeias, americanas, em Tóquio (Japão), em Nankin (China), Florianópolis (UFSC), Rio de Janeiro (UERJ), São Paulo (USP). Atualmente é professor visitante na Universidade de São Paulo (IEA-USP. Entre as suas publicações destacam-se: A linha de pó. A cultura bororo entre tradição, mutação e auto-representação (Annablume, 2012); Fake in China (EdUFAL, 2011); A cidade polifônica (Studio Nobel, 2011), Comunicação visual (Ed. Brasiliense, 2009); Fetichismos visuais (Ed. Atelier, 2008); Culturas eXtremas (DpA, 2005), Sincretika. Explorações etnográficas sobre artes contemporâneas (Studio Nobel, no prelo). 